Article

\title{
Identification of Odor Active Compounds in Physalis peruviana L.
}

\author{
Małgorzata A. Majcher ${ }^{1,+}+\mathbb{D}$, Magdalena Scheibe ${ }^{2,+}+\mathbb{D}$ and Henryk H. Jeleń ${ }^{1, *(\mathbb{C})}$ \\ 1 Faculty of Food Science and Nutrition, Poznań University of Life Sciences, Wojska Polskiego 31, \\ 60-624 Poznań, Poland; majcherm@up.poznan.pl \\ 2 Department of Analytical Chemistry, Chemical Faculty, Gdańsk University of Technology, \\ Gabriela Narutowicza 11/12, 80-233 Gdańsk, Poland; magdalena.scheibe@gmail.com \\ * Correspondence: henrykj@up.poznan.pl; Tel.: +48-61-8487273 \\ + These authors contributed equally to the research.
}

Academic Editor: Jorge Ruiz-Carrascal

Received: 8 December 2019; Accepted: 3 January 2020; Published: 7 January 2020

\begin{abstract}
The volatiles of cape gooseberry fruit (Physalis peruviana L.) were isolated by solvent-assisted flavor evaporation (SAFE), odor active compounds identified by gas chromatography-olfactometry (GC-O) and gas chromatography-mass spectrometry (GC-MS). Quantitation of compounds was performed by headspace-solid phase microextraction (HS-SPME) for all but one. Aroma extract dilution analysis (AEDA) revealed 18 odor active regions, with the highest flavor dilution values (FD = 512) noted for ethyl butanoate and 4-hydroxy-2,5-dimethylfuran-3-one (furaneol). Odor activity values were determined for all 18 compounds and the highest was noted for ethyl butanoate $(\mathrm{OAV}=504)$, followed by linalool, $(E)$-non-2-enal, (2E,6Z)-nona-2,6-dienal, hexanal, ethyl octanoate, ethyl hexanoate, butane-2,3-dione, and 2-methylpropanal. The main groups of odor active compounds in Physalis peruviana L. were esters and aldehydes. A recombinant experiment confirmed the identification and quantitative results.
\end{abstract}

Keywords: Physalis peruviana L.; cape gooseberry; goldenberry; flavor; odor-active; aroma; sensory analysis; SAFE; HS-SPME; GC-O; GC-MS

\section{Introduction}

Fruits, especially berries, have been shown to provide important benefits because of their high content of vitamins, minerals, and antioxidants [1]. The fruits featured by the highest content of nutrient-rich compounds are commonly known as the "superfruits", and supplementation of the human diet with superfruits provides many health benefits [2]. In well-developed countries, superfruits is more of a marketing rather than a scientific term and promotes the demand for rare fruits that can be consumed and used as ingredients by manufacturers of functional foods, nutraceuticals, and beverages. Therefore, food and medicinal products based on these kinds of fruit are growing more popular among consumers. They can be used to enrich the diet with new flavors while providing many natural ingredients which exhibit significant health benefits [2].

Polyphenols with a high antioxidant capacity are the most common compounds, which can be found in superfruits. Apart from the aforementioned compounds, superfruits contain a significant content of different terpenes, which determine the flavor of fruits and exhibit bioactive properties. Among others, $\alpha$-phellandrene and $\beta$-myrcene exhibit antioxidant properties, limonene and $p$-cymene have antimicrobial, antidiabetic, antifungal, antibacterial, anti-nociceptive, and anti-inflammatory properties, respectively [3-6]. Considerable interest led to the increase of the number of research and publications focusing on the health benefits of superfruits $[7,8]$. 
Currently, one of the most interesting is Physalis peruviana L., which is a solanaceous, herbaceous, semi-shrub, upright, and perennial in subtropical zones plant, native to tropical South America. In Colombia, $P$. peruviana L.(known as a cape gooseberry or goldenberry) is cultivated in regions between $1500 \mathrm{~m}$ and $3000 \mathrm{~m}$ above sea level and can grows until it reaches $0.6 \mathrm{~m}$ to $0.9 \mathrm{~m}$, and in some cases can grow up to $1.8 \mathrm{~m}$. Cape gooseberry fruits are round berries with an average diameter of $20-25 \mathrm{~mm}$ and an approximate weight of $4-5 \mathrm{~g}$, protected by an accrescent calyx and covered by a brilliant resinous-yellow peel, containing inside around 100 to 200 small seeds [9,10]. Fruits possess antispasmodic, diuretic, antiseptic, sedative, analgesic properties, and also help to fortify the optic nerve, throat trouble relief, and elimination of intestinal parasites and amoeba. There have also been reported antidiabetic properties, recommending the consumption of five fruits a day. There are studies indicating that eating the fruit of the cape gooseberry reduces blood glucose after $90 \mathrm{~min}$ postprandial in young adults, causing a greater hypoglycemic effect after this period [11]. The cape gooseberry is extensively used as a medicinal herb for treating diseases such as cancer, malaria, asthma, hepatitis, dermatitis, and rheumatism [12]. So far, there are no studies that indicate possible adverse effects. Generally, P. peruviana L. is an attractive fruit for international markets thanks to its important nutritional and medicinal properties. Nowadays, the berries can be found in the form of jams, raisins, and chocolate-covered candies, juices, pomace, and other products, or sweetened with sugar as a snack [13].

In our previous research, we carried out a study on the terpene profile in P. peruviana L. berries, extracted and estimated via different preparation and analytic methods [14,15]. This work is focused on the identification of odor-active flavor compounds in cape gooseberries using the molecular sensory approach [16]. The volatile fraction of fruit was obtained by applying solvent-assisted flavor evaporation (SAFE) and headspace solid-phase microextraction (HS-SPME) techniques [16,17], and analyzed via gas chromatography-olfactometry (GC-O) with aroma extract dilution analysis (AEDA) and gas chromatography-mass spectrometry (GC-MS) methods $[18,19]$. Odor activity values (OAV) for the key odorants were determined.

\section{Results}

\subsection{Sensory Characterization of Cape Gooseberry Fruit (Physalis peruviana L.)}

In the first experiment, the cape gooseberry fruit was subjected to aroma profile analysis. For that reason, eight odor descriptors, caramel, cotton candy, strawberry, citrus, fermented/acid, melon, gooseberry (associated with Ribes uva-crispa fruit), and vanilla, chosen in a preliminary section, were evaluated by the sensory panel. Results presented in Figure 1 illustrate that the overall aroma of the P. peruviana fruit pronounced strong caramel and cotton candy notes followed by strawberry-like, citrus, acid, and vanilla notes.

\subsection{Screening the Cape Gooseberry Volatiles for Aroma-Active Compounds by the Means of GC-O AEDA Analysis}

Aroma isolates obtained using SAFE extraction were submitted to GC-O and AEDA analysis, which revealed 18 aroma-active compounds. The authenticity of them was confirmed by GC-O and GC-MS analysis on two columns of different polarity (SPB-5 and Supelcowax-10) and the comparison of retention indices (RI), mass spectra (MS), and odor with authentic standards (Table 1). However, in one case of 2-acetyl-1-pyrroline, the MS signal in full scan was too weak to obtain a good quality spectrum, so it was identified based on all aforementioned methods with the exception of MS spectra comparison. Flavor dilution factors (FD) for analyzed compounds were obtained by sniffing the serially diluted SAFE extracts, which ranged from 4 to 512. Among odorants, two compounds exhibited the highest FD factor (512) - cotton candy smelling furaneol and fruity smelling ethyl butanoate. Linalool was the only odorant representing terpenoids with a FD of 256. FD values of 128 were attributed to ethyl octanoate, 3-methylsulfanylpropanal (methional), and 2,3-diethyl-5-methylpyrazine. 


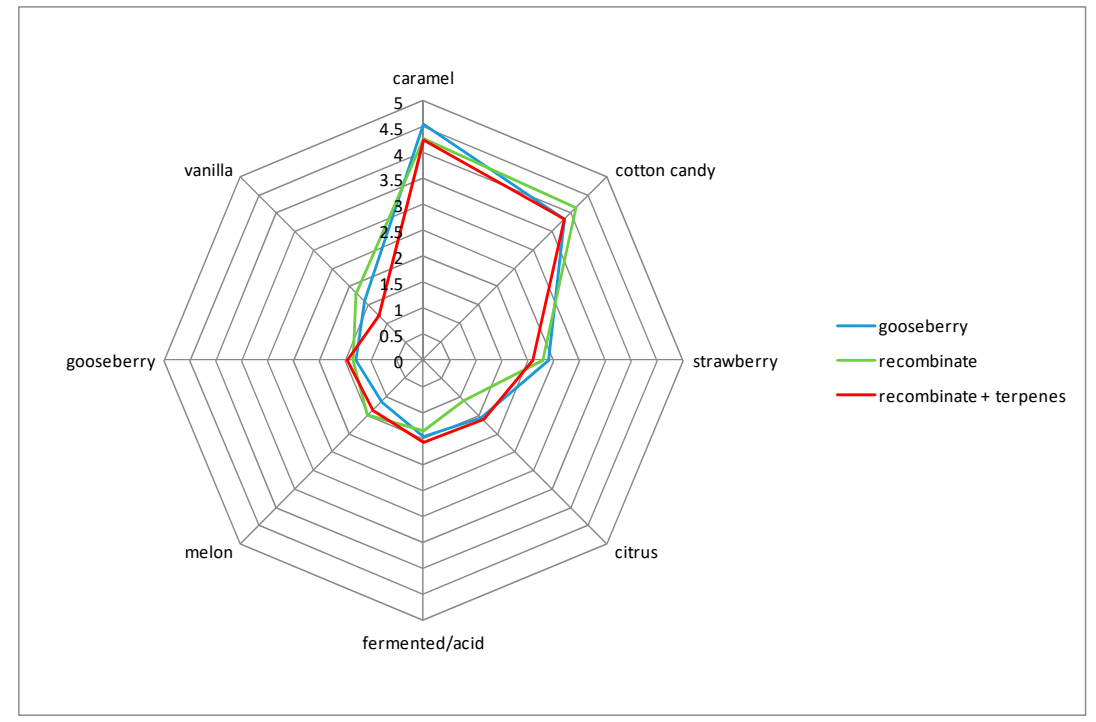

Figure 1. Sensory aroma profiles of a cape gooseberry fruit, its recombinant, and recombinant with addition of terpenes.

Table 1. Key odorants identified in cape gooseberry fruit using gas chromatography-olfactometry with aroma extract dilution analysis (GC-O AEDA).

\begin{tabular}{cccccc}
\hline \multirow{2}{*}{ No } & Compound & odor & $\begin{array}{c}\text { RI } \\
\text { Supelcowax-10 }\end{array}$ & $\begin{array}{c}\text { RI } \\
\text { SPB-5 }\end{array}$ & FD \\
\hline 1 & & & 900 & $<600$ & 4 \\
2 & 2-Methylpropanal & fruity & 950 & 750 & 4 \\
3 & Ethyl 2-methyl propanoate & fruity, anise-like & 980 & $<600$ & 16 \\
4 & butane-2,3-dione & buttery & 1027 & 802 & 512 \\
5 & Ethyl butanoate & fruity & 1072 & 803 & 8 \\
6 & Hexanal & fresh grass & 1200 & 1002 & 16 \\
7 & Ethyl hexanoate & fruity & 1287 & 998 & 16 \\
8 & Octanal & rancid, citrus & 1292 & 978 & 8 \\
9 & Oct-1-en-3-ol & mushroom & 1350 & 911 & 8 \\
10 & 2-Acetyl-1-pyrroline & popcorn & 1419 & 1195 & 128 \\
11 & Ethyl octanoate & fruity & 1450 & 907 & 128 \\
12 & Methional & boiled potato & 1495 & 1156 & 128 \\
13 & 2,3-Diethyl-5-methyl pyrazine & earthy & 1530 & 1159 & 64 \\
14 & (E)-Non-2-enal & fatty, green & 1550 & 1101 & 256 \\
15 & B-Linalool & fruity & 1580 & 1150 & 64 \\
16 & E2, Z6)-Nona-2,6-dienal & cucumber & 1640 & 1048 & 8 \\
17 & 2-Phenylacetaldehyde & rosy, honey-like & 1901 & 1118 & 64 \\
18 & 2-Phenylethanol & flowery, honey-like & 2015 & 1080 & 512 \\
\hline
\end{tabular}

RI-Retention indices on a Supelcowax-10 and SPB-5 columns.

Figure 2 shows the aromagram (A) with FD values and the total ion current (TIC) GC-MS chromatogram on Supelcowax-10 column (B) of SAFE extract. Aromagram represents intensities of compounds sniffed at olfactory port of GC-O with AEDA approach and shows the location of key odorants on the GC-MS chromatogram of volatile compounds. 


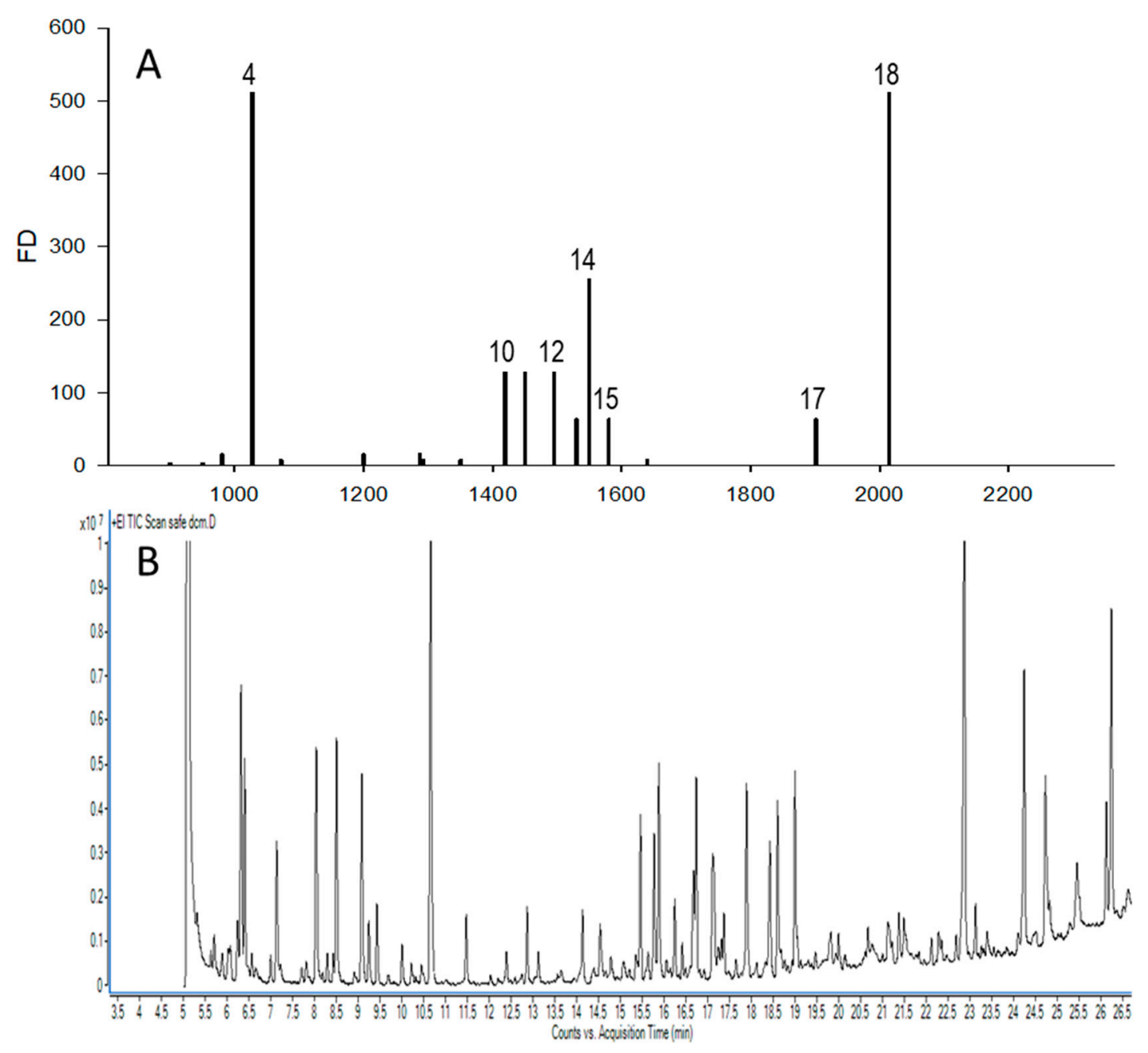

Figure 2. Compilation of aromagram (A) and TIC chromatogram (B) of odor active and volatile compounds in cape gooseberry fruit. Compounds number on (A) correspond to those in Table 1.

To determine the odor activity values (OAV) for compounds identified using AEDA procedure, quantitation was performed using headspace solid phase microextraction (HS-SPME) with a standard addition method for all compounds but one (furaneol). To quantify compounds of interest, their linear range was determined. Standards of compounds of interest were added to sample to construct calibration curve with its intercept, indicating concentration of particular compounds. Concentration ranges of added standards were determined based on peak areas of compounds of interest. The highest linear ranges were noted for esters—ethyl butanoate and ethyl octanoate—up to 3000 and $2000 \mu \mathrm{g} / \mathrm{kg}$, respectively (addition of 500-3000 and 100 to $2000 \mu \mathrm{g} / \mathrm{kg}$ concentrations, respectively). Hexanal and butane-2,3-dione were linear up to $1000 \mu \mathrm{g} / \mathrm{kg}$, whereas for the majority of the remaining compounds, a linear range of up to $200 \mu \mathrm{g} / \mathrm{kg}$ was achieved. For oct-1-ene-3-ol, ethyl 2-methylpropanoate linearity ranged up to $20 \mu \mathrm{g} / \mathrm{kg}$. For ethyl butanoate and ethyl hexanoate the regression coefficient of the curve was 1.000, for hexanal, ethyl octanoate, and 2-phenylacetaldehyde was 0.999, and only for octanal $\left(\mathrm{r}^{2}=0.969\right)$, (E)-non-2-enal $(0.968)$, and 2-phenylethanol $(0.978)$ were lower than 0.99 . As it was impossible to get a reliable standard addition curve for 2,3-diethyl-5-methyl pyrazine its peak area (HS-SPME) was compared to $0.1 \mu \mathrm{g} / \mathrm{kg}$ of authentic standard. It was assumed that its concentration was $<0.1 \mu \mathrm{g} / \mathrm{kg}$, as 2,3-diethyl-5-methyl pyrazine peak in sample had a smaller area than the standard. Similarly, the concentration of 2-acetyl-1-pyrroline was assumed to be less than $0.01 \mu \mathrm{g} / \mathrm{kg}$, as it was not possible to observe 2-acetyl-1-pyrroline significant peak in the fruit sample. Furaneol was the only compound quantified with a SIDA approach using deuterated analogue ${ }^{13} \mathrm{C}_{2}$-furaneol. 
Based on quantitative analysis and OT (in water, [20]), OAV values for 15 compounds $>1$ were calculated (Table 2). The highest OAV value was noted for ethyl butanoate, followed by linalool. High OAV values were also noted for aldehydes-(E)-non-2-enal, (E,Z)-nona-2,6-dienal, and hexanal. To verify the OAV results, a reconstitution experiment was prepared. As can be seen on Figure 1, the odor notes and their intensities for gooseberry and the recombinant closely resembled each other. Also, an additional sample was prepared using recombinant, to which terpenes identified earlier in gooseberry [14] were added. In this case, no significant differences were noted, proving that none of the numerous terpenes identified earlier contributed significantly to the flavor of cape gooseberry.

Table 2. Concentration, odor thresholds, and odor activity values of aroma active compounds of cape gooseberry fruit.

\begin{tabular}{cccc}
\hline Compound & $\begin{array}{c}\text { OT } \\
{[\mu \mathrm{g} / \mathrm{L}]}\end{array}$ & $\begin{array}{c}\text { Concentration } \\
{[\mu \mathrm{g} / \mathbf{k g}]}\end{array}$ & OAV $^{\mathbf{c}}$ \\
\hline Ethyl butanoate & 0.76 & 383.0 & 504 \\
$\beta$-Linalol & 0.089 & 32.0 & 360 \\
$(E)-$ Non-2-enal & 0.08 & 24.0 & 300 \\
$(2 E$, 6Z)-Nona-2,6-dienal & 0.02 & 5.0 & 250 \\
Hexanal & 4.50 & 450.0 & 100 \\
Ethyl octanoate & 5.00 & 411.0 & 82 \\
Furaneol & 30.0 & 1350.0 & 45 \\
Ethyl hexanoate & 1.20 & 45.0 & 38 \\
Butane-2,3-dione & 15.0 & 500.0 & 33 \\
2-Methylpropanal & 1.90 & 50.0 & 26 \\
Octanal & 0.70 & 15.0 & 21 \\
Ethyl 2-methyl propanoate & 0.089 & 1.8 & 20 \\
Methional & 0.20 & 36.0 & 18 \\
2-Phenylacetaldehyde & 4.00 & 25.0 & 3 \\
Oct-1-en-3-ol & 1.00 & 3.0 & $<1$ \\
2,3-Diethyl-5-methyl pyrazine & 1.00 & $<0.1$ & $<1$ \\
2-Phenylethanol & 1000 & 65.0 & $<1$ \\
2-Acetyl-1-pyrroline & 0.1 & $<0.01$ & 3 \\
\hline
\end{tabular}

a_odor thresholds in water [20]. ${ }^{b}$-mean values based on three replicates with RSD value $\leq 12 \%$. ${ }^{\mathrm{c}}$ —odor activity values calculated by dividing the concentration of an analyte by its odor threshold value.

\section{Discussion}

Experiments devoted to analysis of aroma/volatile compounds of cape gooseberry were carried out by several authors. However, in gooseberry aroma analysis, no complete approach consisting of AEDA and OAV has been performed. Berger and colleagues [21] analyzed volatile compounds present in cape gooseberry, and also those responsible for the aroma already in 1989, employing a complex extraction procedure for the isolation of compounds of interest. It allowed authors to identify 5 terpene hydrocarbons, 28 alcohols (including 6 terpene ones), 12 aldehydes, 13 ketones, 26 acids, 51 esters, 7 lactones, and 5 other compounds. Interestingly, among volatiles identified, $8-12$ odor impressions were recognized and compounds responsible for them were identified. Methyl-2-methylbutanoate (fruity), methoxy furanone (caramel), 3-methylbutyric acid (sweaty), $\beta$-damascenone (raspberry-like), $\beta$-ionone (violet), 4-octanolide (coconut), 5-octanolide (sweet-nutty), and hydroxyfuranone (roasted almonds) were the main odoriferous compounds described by authors, however their mutual concentrations/intensities have not been determined. The complex extraction procedure resulted in identification of odor active lactones, 3-methylbutyric acid, as well as damascenone and $\beta$-ionone, which were not identified in our study. This could be a result of either sample preparation differences and/or other composition of gooseberry fruit having been analyzed.

Liquid/liquid extraction using dichloromethane was also used for extraction of volatile and flavor compounds by Ylmaztekin [22], who identified 83 compounds in fruit of Physalis peruviana, where dominating (in area\%) were alcohols and lactones, followed by esters and terpenes. Ylmaztekin also 
investigated main odorants, determining OAV values for them. Gamma octalactone (4-octanolide) was described as fruity, apricot had the highest $\mathrm{OAV}$ of 46.9 , followed by gamma hexalactone (4-hexanolide), which was described as creamy, coconut (OAV 6.1). The next important odorants identified were ethyl octanoate, 2-heptanone, nonanal, hexanal, and citronellol (all with OAV $>2$ ), followed by 2-methyl-1-butanol, benzyl alcohol, 2-phenylethanol, 1-heptanol, ethyl decanoate, and 1-butanol (with OAV 1.0-1.6). Hexanal, ethyl octanoate, and 2-phenylethanol were identified in our study as key odorants as well. When the extraction method was changed by the same author from LLE to SPME ${ }^{28}$, the area \% of particular groups of compounds substantially changed as well: the amount of lactones decreased tenfold (from 24.06 to $2.09 \%$ ), amount of acids decreased from 5.05 to $0.90 \%$, whereas the area \% of esters substantially increased (from 11.7 for LLE to 38.5 for SPME). Similarly, the area $\%$ of aldehydes and ketones increased when SPME was used for extraction [23].

When volatile compounds of cape gooseberry were investigated using other sorbent-based techniques, in tube extraction (ITEX) terpenes prevailed among the main volatiles [14]. Out of 24 compounds which were quantified using calibration curves, 14 were terpene hydrocarbons or alcohols, followed by 4 esters, 4 alcohols, and 2 aldehydes. Interestingly, the most abundant compound in the examined cape gooseberry was benzaldehyde, followed by ethyl butanoate, 2-methyl-1-butanol, and 1-hexanol.

Our results, which are the first using AEDA to select odor active compounds, show differences in the compounds assumed as key odorants in cape gooseberry compared to previous works. The most striking difference was the absence of lactones in fruits examined by us. The differences noted can be attributed to various extraction methods applied in presented studies, as well as to differences in composition of particular fruit cultivars originating from Colombia, Turkey, or other countries or artefacts formation (as in the case of lactones). The reconstitution experiment indicated no significant differences between fruit aroma and the one obtained from reconstituted aroma based on compounds identified. The study broadens our knowledge on the flavor of exotic fruits flavor and indicates the importance of ethyl butanoate $\beta$-linalool, (E)-non-2-enal, (2E, 6Z)-nona-2,6-dienal, and hexanal as the compounds with the highest $\mathrm{OAV}$ values in gooseberry aroma creation, which may serve as sensory quality markers for this fruit.

\section{Materials and Methods}

\subsection{Fruit Samples}

Samples of cape gooseberry (Physalis peruviana L.) imported from Colombia and purchased at a local supermarket were analyzed. Before analysis, fruit samples (calyx removed) were stored in the freezer at $-25^{\circ} \mathrm{C}$.

\subsection{Chemical Standards}

Solvents, such as methylene chloride and sodium sulfate were obtained from Sigma Aldrich (Poznań, Poland). A homologous series of C6-C24 n-alkanes and the following reference aroma compounds were purchased from Sigma-Aldrich (Poznan, Poland): 2-methylpropanal, ethyl 2-methyl propanoate butane-2,3-dione, ethyl butanoate, hexanal, ethyl hexanoate, octanal, oct-1-en-3-ol, ethyl octanoate, 3-methysulfanylpropanal (methional), 2,3-diethyl-5-methylpyrazine, (E)-non-2-enal, 3,7-dimethylocta-1,6-dien-3-ol ( $\beta$-linalol), (2E,6Z)-nona-2,6-dienal, 2-phenylacetaldehyde, 2-phenylethanol, 4-hydroxy-2,5-dimethyl-3-furanone (furaneol), terpinen-4-ol, $\alpha$-terpineol, $\beta$-myrcene, $\alpha$-terpinolene, $\beta$-pinene, limonene, geraniol, $\beta$-citronellol, and $\gamma$-terpinene. Standards of $1-(3,4-$ dihydro-2H-pyrrol-5-yl)ethanone (2-acetyl-1-pyrroline) and isotopically labelled ${ }^{13} \mathrm{C}_{2}$-furaneol were purchased from Aroma LAB (Freising, Germany). 


\subsection{Isolation Method}

For isolation of volatile/odor active compounds, two methods were used: solvent assisted flavor evaporation (SAFE) and solid phase microextraction (SPME) [16,19]. Prior to SAFE, fruit samples (50 g) were frozen in liquid nitrogen (to quench enzymatic reaction), ground in a mortar and pestle into fine powder, and extracted with methylene chloride $(300 \mathrm{~mL})$ for $2 \mathrm{~h}$ each by shaking it in a horizontal shaker. Afterwards, volatiles were isolated by SAFE distillation and extract was dehumidified with an anhydrous sodium sulfate and concentrated with a Kuderna Danish concentrator (Sigma-Aldrich) to about $400 \mu \mathrm{L}$. The extract flavor resembled that of the fruit. For SPME analysis, $10 \mathrm{~g}$ of prepared fruit powder sample was placed in a $20 \mathrm{~mL}$ headspace vials and capped with PTFE/silicon septa caps. Extraction of volatiles was performed with CAR/PDMS/DVB fiber (Supelco) at $30{ }^{\circ} \mathrm{C}$ during $30 \mathrm{~min}$ using Combipal-type autosampler (Agilent Technologies, Willmington, DE, USA).

\subsection{Gas Chromatography-Olfactometry (GC-O)}

Odor active compounds were identified from SAFE extracts by GC-O on an HP 5890 gas chromatograph using the following capillary columns SPB-5 (30 m $\times 0.53 \mathrm{~mm} \times 1.5 \mu \mathrm{m}$, ) and Supelcowax-10 (30 m $\times 0.53 \mathrm{~mm} \times 1 \mu \mathrm{m})$; both from Supelco, Bellefonte, PA, USA. The GC was equipped with an $\mathrm{Y}$ splitter dividing effluent between in-lab built olfactometry port with humidified air as a make-up flow $(30 \mathrm{~mL} / \mathrm{min})$, and a flame ionization detector. The operating conditions were as follows for the SPB-5 column: initial oven temperature $40^{\circ} \mathrm{C}(1 \mathrm{~min})$, raised at $9{ }^{\circ} \mathrm{C} / \mathrm{min}$ to $180{ }^{\circ} \mathrm{C}$ and at $20^{\circ} \mathrm{C} / \mathrm{min}$ to $280^{\circ} \mathrm{C}$. Operating conditions for the Supelcowax- 10 column were as follows: initial oven temperature, $40^{\circ} \mathrm{C}(2 \mathrm{~min})$, raised to $240{ }^{\circ} \mathrm{C}$ at $9{ }^{\circ} \mathrm{C} / \mathrm{min}$ rate, held for $2 \mathrm{~min}$ isothermally. For all peaks and flavor notes, retention indices were calculated to compare results obtained by GC/MS with literature data. Retention indices were calculated for each compound using a homologous series of C6-C24 n-alkanes.

\subsection{Gas Chromatography/Mass Spectrometry}

The chemical compounds were identified using GC/MS system (Agilent Technologies, Palo Alto, CA, USA): 7890A GC coupled to a 5975C MSD with a Supelcowax-10 column $(30 \mathrm{~m} \times 0.25 \mathrm{~mm} \times$ $0.25 \mu \mathrm{m})$ or SLB-5MS $(25 \mathrm{~m} \times 0.2 \mathrm{~mm} \times 0.33 \mu \mathrm{m})$ column (Supelco, Bellefonte, PA, USA). Operating conditions for GC/MS were as follows: He flow, $32.2 \mathrm{~cm} / \mathrm{sec}$; GC/MS interface, $260{ }^{\circ} \mathrm{C}$, and $280{ }^{\circ} \mathrm{C}$ for polar and non-polar columns, respectively. Oven conditions were the same as for GC-O. Mass spectra were recorded in an electron impact mode (EI, $70 \mathrm{eV}$ ) in a scan range of $m / z$ 33-350. For SPME fiber desorption, $260{ }^{\circ} \mathrm{C}$ temperature was used with splitless injection into $0.75 \mathrm{~mm}$ SPME liner. For all the volatiles except 2-acetyl-1-pyrroline, identification was performed by comparison of mass spectra, retention indices (RI), and odor notes on two columns of different polarities with standards. For 2-acetyl-1-pyrroline, the MS signal of the analyte in the sample was too weak to facilitate mass spectra comparison. In this case, only RI and odor notes of the compound were compared with authentic standard and used in its tentative identification.

\subsection{Aroma Extract Dilution Analysis (AEDA)}

The flavor dilution factor (FD) of each of the odorants was determined by AEDA ${ }^{22}$. The flavor extract $(2 \mu \mathrm{L})$ was injected into a GC column. Odor-active regions were detected by GC-effluent sniffing (GC-O), and three panelists determined the description of the volatiles. The extract was than stepwise diluted $(4,8,16,32$, etc.) by addition of methylene chloride, and each sample of the dilution series was analyzed until no odor was perceivable at the sniffing port. For each odor note, FD factor has been assigned, corresponding to the dilution factor of the highest diluted sample in which the odor was detectable. 


\subsection{Quantitation of Odorants}

For all of the compounds except furaneol, 2-acetylpyrroline, and 2,3-diethyl-5-methylpyrazine, HS-SPME extraction has been performed with standard addition method (standard compounds in increasing concentrations were spiked into fruit sample to get calibration curve from which the concentration of particular compound can be obtained. Linearity for the standard curves was calculated as the regression coefficient $\left(\mathrm{r}^{2}\right)$. Furaneol was quantified based on SAFE using added labelled standard of ${ }^{13} \mathrm{C}_{2}$ furaneol. Quantitation was based on $\mathrm{m} / \mathrm{z} 128$ for furaneol and $\mathrm{m} / \mathrm{z} 130$ for its isotopologue.

\subsection{Aroma Recombination}

For cape gooseberry aroma recombination, stock solution of aroma compounds with OAV $>1$ was prepared in water with an adjusted level of sugar $(11 \mathrm{~g} / 100 \mathrm{~g})$ and $\mathrm{pH}$ was adjusted to 3.9 with citric acid, and mixed in the concentration levels equal to those determined in the cape gooseberry sample.

\subsection{Sensory Evaluation}

Sensory analyses of cape gooseberry samples, as well as recombinants, were evaluated by 10 panelists with experience in sensory descriptive analysis. Aroma profile analyses were performed by orthonasally scoring eight odor qualities on a $10 \mathrm{~cm}$ linear scale anchored on either side for the intensity of attributes as "none" and "very strong". The odor descriptors were determined in preliminary tests. The $5 \mathrm{~g}$ of (sliced) fruit sample or recombinant were placed in $100 \mathrm{~mL}$ glass containers and presented to the panelists, in a way that panelists could not see the content of the vessel. The results from the linear scale were converted into numerical values for data analysis.

Author Contributions: Conceptualization, M.A.M., M.S., and H.H.J.; methodology, M.A.M., M.S., and H.H.J.; resources, M.S.; writing—original draft preparation, M.A.M., M.S.; writing—review and editing H.H.J.; funding acquisition, M.S. All authors have read and agreed to the published version of the manuscript.

Funding: This research was funded by National Science Centre, grant number DEC-2012/07/N/ST4/00629.

Conflicts of Interest: The authors declare no conflict of interest.

\section{References}

1. Zhao, Y. (Ed.) Berry Fruit: Value-Added Products for Health Promotion; CRC Press: Boca Raton, FL, USA, 2007.

2. Steven, G.; Pratt, M.D.; Matthews, K. Super Foods Rx: Fourteen Foods that Will Change Your Life; Harper Collins Publishers: New York, NY, USA, 2005.

3. Ciftci, O.; Ozdemir, I.; Tanyildizi, S.; Yildiz, S.; Oguzturk, H. Antioxidative effects of curcumin, $\beta$-myrcene and 1,8-cineole against 2,3,7,8-tetrachlorodibenzo-p-dioxin-induced oxidative stress in rats liver. Toxicol. Ind. Health 2011, 27, 447-453. [CrossRef] [PubMed]

4. Vuuren, S.F.; Van Viljoen, A.M. Antimicrobial activity of limonene enantiomers and 1,8-cineole alone and in combination. Flavour Frag. J. 2007, 22, 540-544. [CrossRef]

5. Roberto, D.; Micucci, P.; Sebastian, T.; Graciela, F.; Anesini, C. Antioxidant activity of limonene on normal murine lymphocytes: Relation to $\mathrm{H}_{2} \mathrm{O}_{2}$ modulation and cell proliferation. Basic Clin. Pharmacol. Toxicol. 2010, 106, 38-44. [CrossRef] [PubMed]

6. Murali, R.; Saravanan, R. Antidiabetic effect of d-limonene, a monoterpene in streptozotocin-induced diabetic rats. Biomed. Prev. Nutr. 2012, 2, 269-275. [CrossRef]

7. Jamin, E. Superfruits: Are they authentic? Fruit Process. 2009, 19, 170-175.

8. Crozier, S.J.; Preston, A.G.; Hurst, J.W.; Payne, M.J.; Mann, J.; Hainly, L.; Miller, D.L. Cacao seeds are a “Super Fruit": A comparative analysis of various fruit powders and products. Chem. Cent. J. 2011, 5, 5. [CrossRef] [PubMed]

9. Olivares-Tenorio, M.L.; Dekker, M.; Verkerk, R.; van Boekel, A.J.S. Health-Promoting compounds in cape gooseberry (Physalis peruviana L.): Review from a supply chain perspective. Trends Food Sci. Techn. 2016, 57, 83-92. [CrossRef]

10. Puente, L.A.; Pinto-Muñoz, C.A.; Castro, E.S.; Cortés, M. Physalis peruviana Linnaeus, the multiple properties of a highly functional fruit: A review. Food Res. Int. 2011, 44, 1733-1740. [CrossRef] 
11. Rodríguez, S.; Rodríguez, E. Efecto de la ingesta de Physalisperuviana (aguaymanto) sobre la glicemia postprandial enadultosjóvenes. Rev. Médica Val. 2007, 4, 43-52.

12. Salazar, M.; Jones, J.; Chaves, B.; Cooman, A. A model for the potential production and dry matter distribution of cape gooseberry (Physalis peruviana L.). Sci. Hortic. 2008, 115, 142-148. [CrossRef]

13. Ramadan, M.F.; Moersel, J.T. Impact of enzymatic treatment on chemical composition, physicochemical properties and radical scavenging activity of golden berry (Physalis peruviana L.) juice. J. Sci. Food Agric. 2007, 87, 452-460. [CrossRef]

14. Kupska, M.; Jeleń, H.H. In-tube extraction for the determination of the main volatile compounds in Physalis peruviana L. J. Sep. Sci. 2017, 40, 532-541. [CrossRef] [PubMed]

15. Kupska, M.; Wasilewski, T.; Jędrkiewicz, R.; Gromadzka, J.; Namieśnik, J. Determination of terpene profiles in potential superfruits. Int. J. Food Prop. 2016, 19, 2726-2738. [CrossRef]

16. Schieberle, P.; Hofmann, T. Mapping the Combinatorial Code of Food Flavors by Means of Molecular Sensory Science Approach. In Food Flavors. Chemical, Sensory and Technological Properties; Jeleń, H., Ed.; CRC Press: Boca Raton, FL, USA, 2012; pp. 413-438.

17. Li, J.-X.; Schieberle, P.; Steinhaus, M. Characerization of the major odor-active compounds in Thai durian (Durio zibethinus L. 'Monthong') by aroma extract dilution analysis and headspace gas chromatography-Olfactometry. J. Agric. Food Chem. 2012, 60, 11253-11262. [CrossRef] [PubMed]

18. Munafo, J.P., Jr.; Didzbalis, J.; Schnell, R.J.; Steinhaus, M. Insights into the key aroma compounds of mango (Mangifera indica L. Haden) fruits by stable isotope dilution quantitation and aroma simulation experiments. J. Agric. Food Chem. 2016, 64, 4312-4318. [CrossRef] [PubMed]

19. Prosen, H.; Jane, L.; Strli, M.; Rusjan, D. Analysis of free and bound aroma compounds in grape berries using headspace solid-phase microextraction with GC-MS and a preliminary study of solid-phase extraction with LC-MS. Acta Chim. Slov. 2007, 54, 25-32.

20. Van Gemert, L.J.; Odour, T. Compilations of Odour Threshold Values in Air, Water and Other Media; Oliemans Punter \& Partners BV: Zeist, The Netherlands, 2011.

21. Berger, R.G.; Drawert, F.; Kollmannsberger, H. The flavor of cape gooseberry (Physalis peruviana L.). Z. Lebensm Unters. Forsch. 1989, 188, 122-126. [CrossRef]

22. Yilmaztekin, M. Characterization of potent aroma compounds of cape gooseberry (Physalis peruviana L.) fruits grown in Antalya through the determination of odor activity values. Int. J. Food Prop. 2014, 17, 469-480. [CrossRef]

23. Yilmaztekin, M. Analysis of volatile components of cape gooseberry (Physalis peruviana L.) grown in Turkey by HS-SPME and GC-MS. Sci. World J. 2014, 796097. [CrossRef]

Sample Availability: Sample Availability: Not available.

(C) 2020 by the authors. Licensee MDPI, Basel, Switzerland. This article is an open access article distributed under the terms and conditions of the Creative Commons Attribution (CC BY) license (http://creativecommons.org/licenses/by/4.0/). 